\title{
Caracterização de uma População de Cacaueiro para Mapeamento de Genes de Resistência à Vassoura-de-Bruxa e Podridão-Parda*
}

\author{
Alfredo Dantas Neto ${ }^{1}$, Ronan X. Corrêa ${ }^{2}$, Wilson R. Monteiro ${ }^{1}$, Edna D. M. N. Luz ${ }^{3}$, \\ Karina P. Gramacho ${ }^{3} \&$ Uilson V. Lopes ${ }^{1}$ \\ ${ }^{1}$ Seção de Genética; ${ }^{3}$ Seção de Fitopatologia, Centro de Pesquisas do Cacau, Cx. Postal 07, CEP 45600-970, Itabuna, BA; \\ ${ }^{2}$ Departamento de Ciências Biológicas, Universidade Estadual de Santa Cruz, Rodovia Ilhéus-Itabuna, km 16, \\ CEP 45650-000, Ilhéus, BA, e-mail: alfredo@cepec.gov.br
}

(Aceito para publicação em 06/06/2005)

Autor para correspondência: Alfredo Dantas Neto

DANTAS NETO, A., CORRÊA, R.X., MONTEIRO, W.R., LUZ, E.D.M.N., GRAMACHO, K.P. \& LOPES, U.V. Caracterização de uma população de cacaueiro para mapeamento de genes de resistência à vassoura-de-bruxa e podridãoparda. Fitopatologia Brasileira 30:380-386. 2005.

\section{RESUMO}

O cacaueiro (Theobroma cacao) é alvo de diversas enfermidades, sendo que a podridão-parda, causada por Phytophthora spp. é a principal delas mundialmente. Entretanto, no Brasil, a vassoura-de-bruxa causada por Crinipellis perniciosa, é a mais devastadora. A busca de fontes de resistência às doenças é a etapa básica para programas de melhoramento genético e, nesse sentido, este estudo objetivou caracterizar quantitativamente uma progênie oriunda do cruzamento entre os clones SIC-864 e CCN-51, dois genótipos contrastantes para diversas características, inclusive para resistência à vassourade-bruxa e podridão-parda. Foram avaliados em condições de campo o número médio de frutos por planta por ano, porcentagem de frutos sadios, porcentagem de frutos com vassoura-de-bruxa, porcentagem de frutos com podridão-parda, número médio de vassouras vegetativas por planta por ano e número médio de vassouras de almofada floral por planta por ano, durante um período de quatro anos. As estatísticas descritivas da produtividade e da resistência a doenças foram calculadas considerando os valores máximo, médio e mínimo, o desvio padrão, o coeficiente de variação, e a distribuição da freqüência. O coeficiente de repetibilidade foi calculado para estimar a acurácia da variação fenotípica por efeitos ambientais pelos métodos da análise de variância, componentes principais e análise estrutural. Foi demonstrado o caráter segregante dessa progênie para resistência à vassoura-de-bruxa e à podridão-parda e para outras características, mostrando a utilidade da população para estudos de mapeamento genético utilizando marcadores moleculares, visando identificar genes de resistência e "quantitative trait loci" (QTLs) dissimilares dos encontrados no clone Scavina-6, tradicionalmente usado em programas de melhoramento genético do cacaueiro.

Palavras-chave adicionais: Crinipellis perniciosa, Phytophthora spp., Theobroma cacao, melhoramento genético.

\begin{abstract}
Characterization of a cocoa population for mapping of genes of resistance to Witches' Broom and Phytophthora pod rot

Cocoa (Theobroma cacao) is a target for several diseases, the main one being black-pod, caused by Phytophthora spp. However, witches' broom caused by Crinipellis perniciosa is the most devastating cocoa disease in Brazil. The search for sources of disease resistance is the first step in breeding programs. To this end, this study aimed to quantitatively characterize a progeny from the cross between the cocoa clones SIC-864 and CCN-51, two contrastant genotypes for several traits, including resistance to witches' broom and black pod. The progeny was assessed under field conditions for the average number of pods per tree per year, the percentage of healthy pods, the percentage of pods with witches' broom, the percentage of pods with black pod, the average number of vegetative brooms per tree per year and the average number of cushion brooms per tree per year, for a period of four years. The descriptive statistics for productivity and resistance to diseases were computed considering the maximum, the mean and the minimum values, the standard deviation, the coefficient of variation and the distribution of frequency. The repeatability coefficient was computed to estimate the accuracy of the phenotypic measurements through the methods variance analysis, principal components and structural analysis. It was shown that this progeny segregates for resistance to witches' broom, black pod and other traits, thus illustrating its usefulness for studies of genetic mapping using molecular markers, aiming to identify genes of resistance and quantitative trait loci (QTLs) different from those found in the Scavina-6 clone, traditionally used in cocoa breeding programs.
\end{abstract}

Additional keywords: Crinipellis perniciosa, Phytophthora spp., Theobroma cacao, breeding programs.

\section{INTRODUÇÃO}

*Parte da Dissertação de Mestrado do primeiro autor. Universidade Estadual de Santa Cruz (2004).
Onde é cultivado, o cacaueiro (Theobroma cacao L.) sempre foi alvo de várias doenças de grande importância 
econômica. A podridão-parda dos frutos do cacaueiro ou podridão-de-phytophthora, causada por Phytophthora spp. é, em termos mundiais, a principal delas, pois ocorre em todos os países produtores de cacau. Outras doenças como a vassoura-de-bruxa, causada por Crinipellis perniciosa (Stahel) Singer, a monilíase ou podridão-demoniliophthora causad por Moniliophthora roreri (Cif.) Evans et al., e a murcha-vascular-estriada ou vascularstreak-dieback, causada por Oncobasidium theobromae Talbot \& Keane, causam perdas maiores que a podridãode-phytophthora mas são restritas a determinadas regiões do mundo.

No Brasil, a podridão-parda ocorre em todos os estados produtores de cacau e as perdas por ela causadas variam de 20 a $30 \%$ da produção de frutos (Medeiros, 1977). No entanto, na Bahia, principal estado produtor, perdas de 70 a $80 \%$ da produção eram comuns, até o final da década de 80 (Luz et al., 1997). Nos anos 90, impactos econômicos com a podridão-parda no Brasil só foram registrados até 1993. Por se tratar de uma doença muito influenciada por altas precipitações pluviométricas, principalmente nos meses mais frios do ano, com o retorno dessas precipitações nos últimos anos, os danos causados pela podridão-parda voltaram a se elevar (Luz \& Silva, 2001).

A partir de 1989, com o primeiro relato na região cacaueira baiana do fungo $C$. perniciosa, causador da vassoura-de-bruxa (Pereira et al., 1989), iniciou-se nessa região um processo de empobrecimento provocado pela redução de até $100 \%$ da produção de cacau, em diversas propriedades rurais.

Crinipellis perniciosa infeta os lançamentos foliares novos, os frutos em desenvolvimento e as almofadas florais podendo, até, provocar a morte da planta quando afetada por sucessivos ciclos do patógeno associados a fatores abióticos (Andebrhan, 1984; Queiroz et al., 2003).

Uma das alternativas encontradas para se manejar a vassoura-de-bruxa é o emprego de variedades resistentes e de alta produtividade, desenvolvidas em programa de melhoramento genético do cacaueiro. Essa medida de controle é fundamental haja vista os controles químico e cultural terem se mostrado onerosos e ineficazes quando não executados rigorosamente de acordo com as recomendações técnicas da pesquisa, e antieconômicos em se tratando de lavouras formadas por variedades de alta suscetibilidade e de baixa produtividade (Pinto \& Pires, 1998).

Após 15 anos de convivência com a vassoura-debruxa, a lavoura cacaueira começa a dar sinais de recuperação devido à utilização de cultivares resistentes. Entretanto, a grande maioria delas, tanto as seminais quanto as clonais, descende de uma única fonte de resistência, o clone Scavina-6. Por isso, é necessário identificar novas fontes de resistência, obter novos marcadores moleculares ligados a "quantitative trait loci" (QTL's) associados à resistência, objetivando a ampliação da base genética da resistência do cacaueiro à vassourade-bruxa. Para isso, a avaliação fenotípica acurada de populações de mapeamento para a resistência é fundamental. O desenvolvimento ou seleção de variedades que comportam um número maior de genes ligados à resistência também é uma estratégia interessante para uma resistência mais estável, durável e efetiva, dificultando o aumento da população e a evolução do fungo sobre tais materiais (Pinto \& Pires, 1998).

Os clones SIC-864 e CCN-51 de cacaueiro são contrastantes para vários caracteres, inclusive para resistência à vassoura-de-bruxa e podridão-parda (Wadsworth et al., 2003). Neste trabalho, objetivou-se caracterizar fenotipicamente uma progênie $F_{1}$ originada do cruzamento entre esses clones, baseando-se na avaliação de várias características agronômicas de interesse como a resistência à vassoura-de-bruxa e à podridão-parda, visando a sua utilização em estudos de mapeamento com aplicação ao programa de melhoramento genético do cacaueiro.

\section{MATERIAL E MÉTODOS}

\section{Material genético}

A população de cacaueiro utilizada nesse estudo foi uma progênie $\mathrm{F}_{1}$ de 67 plantas, implantada por mudas seminais no ano de 1996 na área experimental do Centro de Pesquisas do Cacau da CEPLAC, Ilhéus, BA, originada do cruzamento entre os clones SIC-864 (Catongo) e CCN-51.

O Catongo é uma mutação para o albinismo do cacaueiro da variedade comum, recebendo esse nome por ter sido identificado na fazenda Catongo, na segunda metade dos anos 30, na antiga localidade de Pirangi, hoje município de Itajuípe (BA). Possui frutos brancoesverdeados quando imaturos e amarelos quando maduros, sendo que a casca é quase lisa. Sua principal característica, sob o ponto de vista morfológico, é a despigmentação no interior das sementes e também das folhas tenras, embora ocorram frutos que apresentam sementes ocres por efeito de polinização cruzada-xenia-(Bondar, 1958). Quanto à resistência a enfermidades, é altamente suscetível à vassoura-de-bruxa (Gramacho et al., 1992) e apresenta resistência moderada à podridão-parda (Medeiros, 1965).

O CCN-51 ("Colección Castro Naranjal") é oriundo de uma planta $F_{1}$ do cruzamento entre ICS-95 X IMC-67, cruzada com um clone nativo do oriente equatoriano denominado "Canelos". Produz frutos vermelho-arroxeados quando imaturos, passando a amarelo-alaranjados quando maduros, com casca levemente enrugada e sementes com coloração interna púrpura clara. Quando comparado com outras variedades locais do Equador, tem demonstrado ser resistente à vassoura-de-bruxa e sua suscetibilidade à podridão-parda é menor quando comparada à outra enfermidade comum no Equador, a monilíase (Campo \& Andía, 1997); no Brasil, a resistência do $\mathrm{CCN}-51$ à vassoura-de-bruxa foi confirmada por Pires (2003). 


\section{Avaliações fenotípicas}

Durante os últimos cinco anos foram feitas avaliações de dados fenotípicos da progênie. As coletas dos dados variaram em número a cada ano, sendo seis coletas em 2000, onze coletas em 2001, dez coletas em 2002 e 11 coletas em 2003. Neste estudo, foram analisados os dados referentes à porcentagem de frutos sadios (\%FS), porcentagem de frutos com vassoura-de-bruxa (\%FVB), porcentagem de frutos com podridão-parda (\%FPP), número médio de vassouras vegetativas por planta por ano (NVV), número médio de vassouras tipo almofada floral por planta por ano (NVA) e número médio de frutos produzidos por planta por ano (PROD). Foram calculadas estatísticas descritivas da produtividade e da resistência a doenças com base nos valores máximo, mínimo e médio, no desvio padrão e coeficiente de variação, e na distribuição da freqüência com auxílio do programa Genes (Cruz, 2001); foi analisada a repetibilidade dessas características para estimar a acurácia da variação fenotípica por efeitos ambientais, pelos métodos da análise de variância (ANOVA), componentes principais (covariância e correlação) e análise estrutural (covariância e correlação) conforme descrito por Cruz \& Regazzi (1997), utilizandose também o programa Genes (Cruz, 2001). Os coeficientes de repetibilidade, com o emprego dessas metodologias, têm sido utilizados para estimar o número mínimo de observações para avaliar sintomatologia (Liberato et al., 2004) e outras características agronômicas de interesse (Dias \& Kageyama, 1998).

\section{RESULTADOS E DISCUSSÃO}

$\mathrm{Na}$ estatística descritiva das variáveis analisadas (Tabela 1), a variável porcentagem de frutos com vassourade-bruxa foi a que apresentou maior coeficiente de variação. Os coeficientes de variação foram bastante elevados para todas as variáveis. Em geral, a incidência de frutos doentes com vassoura-de-bruxa foi superior à incidência de frutos doentes com podridão-parda. Verificou-se ainda que a porcentagem de frutos sadios e com vassoura-de-bruxa foram as variáveis que atingiram os percentuais máximos de incidência mas, com diferentes coeficientes de variação, que foi maior para a porcentagem de frutos com vassoura, o que mostra uma grande variabilidade no nível de resistência das plantas $F_{1}$. Apesar de apresentar um coeficiente de variação menor que o da porcentagem de frutos com vassoura-de-bruxa, a média de frutos com podridão-parda foi próxima à de frutos com vassoura-debruxa, o que também ocorreu com o percentual mínimo de frutos com ambos os sintomas. Adicionalmente, de acordo com os percentuais máximos, percebeu-se que houve uma menor incidência de frutos com podridão-parda do que com vassoura-de-bruxa, podendo supor que essa progênie é mais suscetível à vassoura-de-bruxa do que a podridão-parda, em frutos.

As variáveis número de vassouras vegetativas e de vassouras de almofada floral apresentaram coeficientes de variação muito próximos, entretanto, a ocorrência de vassouras vegetativas foi mais comum, com maior média e maior valor máximo (Tabela 1). Apesar de o número médio e máximo de vassouras vegetativas ter sido superior ao de vassouras de almofada floral, constatou-se o mesmo valor mínimo para ambas características (Tabela 1). Isso permitiu sugerir que, na média, a progênie em estudo é mais suscetível à incidência de vassouras vegetativas do que de vassouras de almofada floral. Outros materiais avaliados no Centro de Pesquisa do Cacau (Cepec) também apresentaram variação na intensidade da vassoura-de-bruxa em almofadas florais e ramos. Por exemplo, Pires (2003) identificou que seleções de variedades tradicionais da Bahia (série Cepec) e das séries SIC, SIAL e EEG apresentaram maior suscetibilidade a vassouras vegetativas do que a vassouras de almofada floral. Por outro lado, esse autor identificou também que seleções das séries RIM, MEX e UF apresentaram maior suscetibilidade a vassouras de almofada floral do que a vassouras vegetativas.

$\mathrm{Na}$ distribuição de freqüência observou-se que as maiores produções concentraram-se em um menor número de plantas (Figura 1A), o que evidenciou que a característica produtividade de ambos os genitores foi transferida para poucos indivíduos da progênie. Convém ressaltar que a progênie está plantada em espaçamento 3,0 $\mathrm{m} X 1,5 \mathrm{~m}$, diferente do espaçamento tradicional utilizado para a cultura do cacau, que é de $3,0 \mathrm{~m} \mathrm{X} 3,0 \mathrm{~m}$; isso certamente contribuiu para uma produtividade menor e maior efeito de erro na determinação da produção, devido à maior competição entre plantas.

Os maiores percentuais de frutos sadios ocorreram predominantemente em poucas plantas (Figura 1B), podendo-se atribuir isso à elevada incidência de vassourade-bruxa e podridão-parda o que contribui para aumentar a quantidade de inóculo no campo e assim propiciar uma boa avaliação da progênie. Plantas com resistência a ambas doenças e produtividade combinando características do

TABELA 1 - Produtividade e sintomatologia de 67 plantas $F_{1}$ do cruzamento SIC-864 X CCN-51 de cacaueiro (Theobromae cacao), com base nas avaliações fenotípicas durante quatro anos (2000 a 2003)

\begin{tabular}{lcccccc}
\hline & \multicolumn{5}{c}{ Produtividade e Sintomatologia* } \\
\cline { 2 - 7 } & PROD & \%FS & \%FVB & \%FPP & NVV & NVA \\
\hline Máximo & 19,50 & 100 & 100 & 65 & 7,5 & 5,3 \\
Mínimo & 0,25 & 14 & 4 & 3 & 0,3 & 0,3 \\
Média & $\mathbf{6 , 4 1}$ & 52,52 & 27,06 & 29,03 & 2,09 & 1,72 \\
Desvio p adrão & 4,55 & 17,16 & 20,75 & 12,36 & 1,46 & 1,20 \\
CV\% & 71,02 & 32,67 & 76,67 & 42,59 & 70,13 & $\mathbf{6 9 , 6 5}$ \\
\hline
\end{tabular}

*PROD (número médio de frutos produzidos por planta por ano); \% FS (porcentagem de frutos sadios); \%FVB (porcentagem de frutos com vassoura-de-bruxa); \%FPP (porcentagem de frutos com podridão-parda); NVV (número médio de vassouras vegetativas por planta por ano); NVA (número médio de vassouras tipo almofada por planta por ano). 


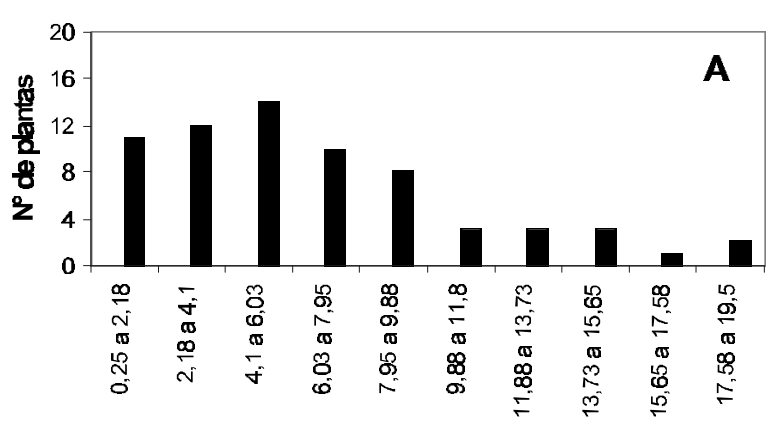

Número médio de frutos produzidos por ano

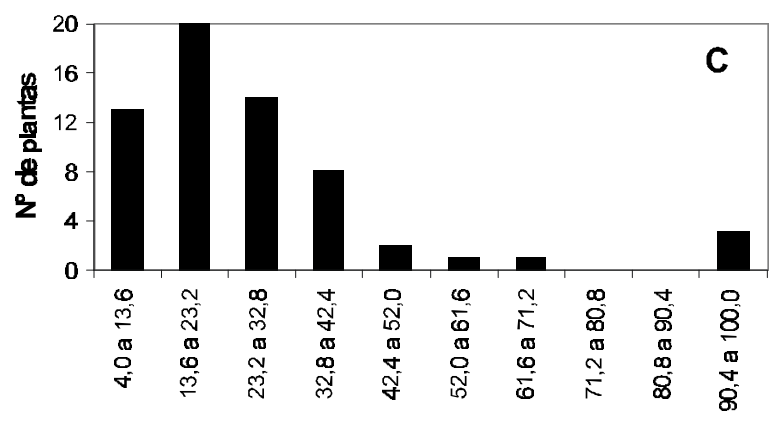

$\%$ de frutos com vassoura-de-bruxa

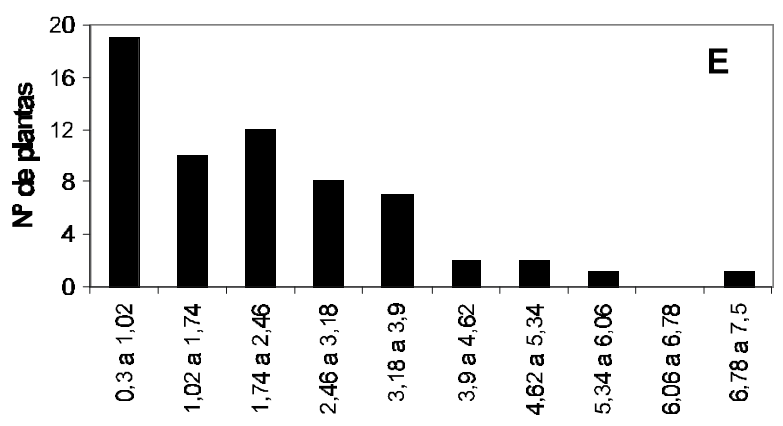

Número médio de vassouras vegetativas por planta
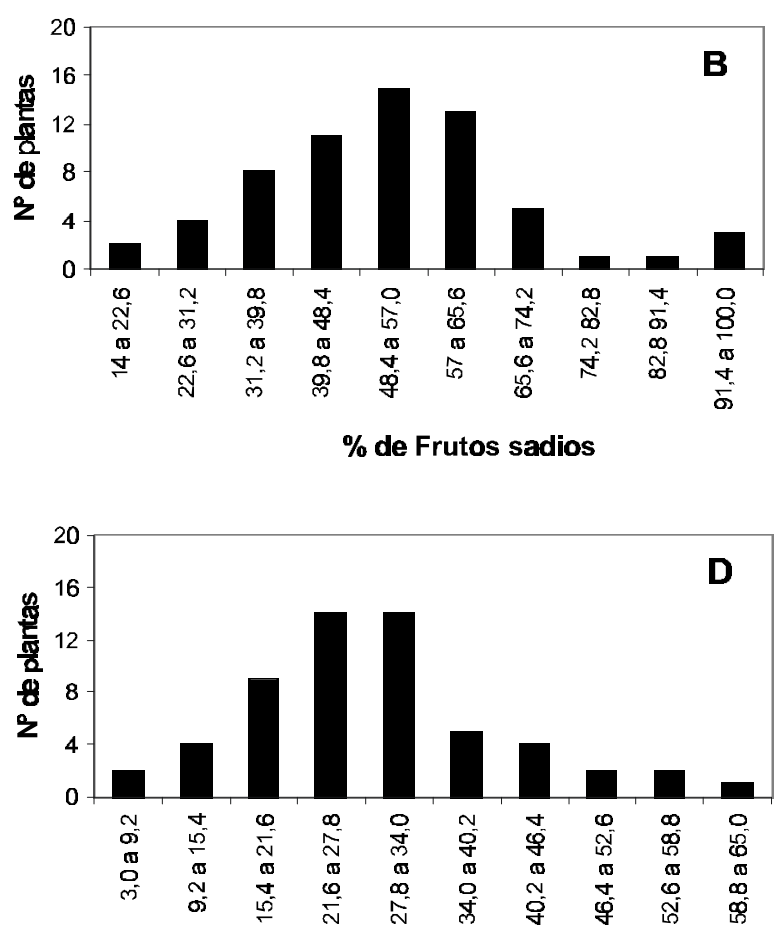

$\%$ de frutos com podridão parda

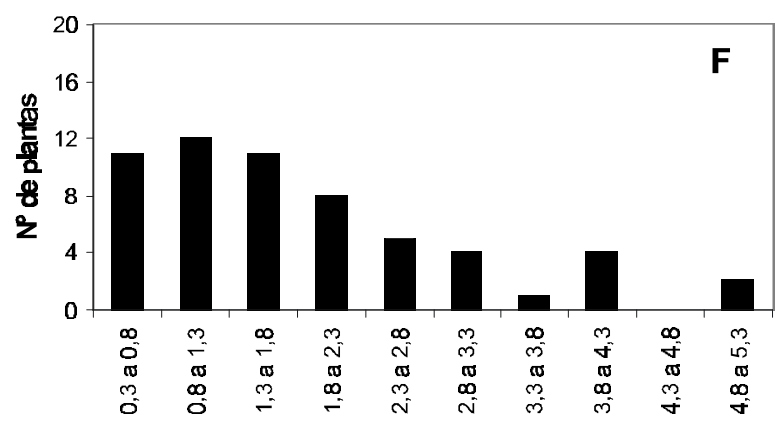

Número médio de vassoura-de-bruxa por planta

FIG. 1 - Distribuição da frequiência de 67 plantas F1 do cruzamento SIC-864 X CCN-51, relativa ao número médio de frutos produzidos por planta de cacaueiro (Theobromae cacao) (A), porcentagem de frutos sadios (B), porcentagem de frutos com vassoura-de-bruxa (C), porcentagem de frutos com podridão-parda (D), número médio de vassouras vegetativas por planta (E) e número médio de vassouras tipo almofada floral por planta $(\mathrm{F})$.

SIC-864 e CCN-51 mostram a importância desta progênie para o mapeamento de QTLs associados à resistência e para o programa de melhoramento do cacaueiro. Muitas plantas da progênie mostraram-se susceptíveis a ambas doenças, principalmente devido às características do SIC864.

Quando se comparou as variáveis percentual de frutos com vassoura-de-bruxa e com podridão-parda podese observar que somente no primeiro caso houve plantas que apresentaram incidência da doença em 100\% dos frutos (Figura 1C). Adicionalmente observou-se, também, que os percentuais mais elevados de incidência da vassoura-debruxa em frutos ocorreram em poucas plantas (Figura 1C). Por outro lado, observou-se que o percentual máximo de incidência da podridão-parda em frutos foi de $65 \%$ (Figura 1D). Não obstante, deve-se considerar também que a incidência de podridão parda em bilros não foi registrada. Outra observação interessante é que a distribuição de freqüência da porcentagem de frutos com podridão-parda foi próxima de uma distribuição normal (Figura 1D), ao contrário da porcentagem de frutos com vassoura-de-bruxa (Figura 1C), o que permite inferir sobre um maior número de genes de resistência à podridão-parda quando comparado à resistência à vassoura-de-bruxa. Portanto, pode-se supor que, para a população estudada, a resistência à podridão-parda foi de natureza poligênica ao passo que para a vassoura-de-bruxa foi mono ou oligogênica. A natureza poligênica da resistência do cacaueiro à podridão- 
parda também foi evidenciada por Crouzillat et al. (2000) em estudos de mapeamento genético em duas populações segregantes; adicionalmente, Queiroz et al. (2003), estudando outra população segregante para mapeamento, sugeriram que a herança da resistência a vassouras vegetativas pode ter sido proveniente de um único gene dominante; isso permitiu inferir sobre a natureza monogênica ou oligogênica da resistência do cacaueiro à vassoura-de-bruxa. Por outro lado, Niella (2000), comparando um isolado de $C$. perniciosa de Ouro Preto D'Oeste (RO) com outro isolado de Manaus (AM), verificou a existência de especialização fisiológica desse patógeno, ao nível de raça, quando esses isolados foram inoculados sobre os clones SIAL-69 e SCA-6. O isolado de Ouro Preto D'Oeste conseguiu quebrar a resistência do SCA-6 à vassoura-de-bruxa indicando a ocorrência de resistência vertical no patossistema $C$. perniciosa $x T$. cacao, o que não descarta a possibilidade de ter havido resistência horizontal não detectada no experimento.

Adicionalmente ao fato de o número de vassouras vegetativas e de vassouras de almofada floral terem apresentado coeficientes de variação muito próximos (Tabela 1), observou-se uma distribuição de freqüência também muito semelhante entre estas duas características (Figura 1E e 1F), embora o número de plantas com menor número médio de vassouras vegetativas tenha sido maior, podendo-se inferir um maior nível de resistência da progênie na incidência de vassouras vegetativas. Isso permite sugerir que a pressão de inóculo e as demais condições na área foram adequadas à discriminação de plantas resistentes daquelas susceptíveis no período avaliado. Contudo, com a diminuição da pressão do inóculo natural, optou-se por realizar inoculações artificiais nos indivíduos da população, ampliada em casa de vegetação.

As avaliações das características estudadas foram realizadas a partir de plantas individuais, de modo que as distinções foram inflacionadas pelas diferenças ambientais relativas às suas posições. Por outro lado, as medidas foram repetidas no tempo e a análise de repetibilidade proporcionou um dimensionamento da confiabilidade dos dados.

Os coeficientes de repetibilidade variaram em até duas vezes entre os métodos de estimação para as características vassoura de almofada floral e vassoura vegetativa, sugerindo que essas características tenham sofrido considerável influência ambiental. Por outro lado, a similaridade entre os coeficientes obtidos pelos diferentes métodos para as demais características sugeriu a consistência entre as estimações, indicando que as demais características têm baixa probabilidade de interações entre tratamentos (Tabela 2).

Os valores de $\mathrm{R}^{2}$ foram superiores a cerca de $70 \%$ para as características analisadas, exceto para vassoura vegetativa e vassoura de almofada floral, indicando um

TABELA 2 - Coeficientes de repetibilidade (r) e de determinação $\left(\mathrm{R}^{2}\right)$ estimados por diferentes métodos para produção e sintomatologia em cacaueiro (Theobromae cacao), durante quatro anos (2000 a 2003)

\begin{tabular}{|c|c|c|c|c|c|c|c|c|c|c|c|c|}
\hline \multirow[t]{2}{*}{ Método* } & \multicolumn{2}{|c|}{ Produção } & \multicolumn{2}{|c|}{ Frutos sadios } & \multicolumn{2}{|c|}{$\begin{array}{c}\text { Frutos com } \\
\text { Vassoura- de-bruxa }\end{array}$} & \multicolumn{2}{|c|}{$\begin{array}{c}\text { Frutos com } \\
\text { Podridão-parda }\end{array}$} & \multicolumn{2}{|c|}{$\begin{array}{l}\text { Vassouras } \\
\text { vegetativas }\end{array}$} & \multicolumn{2}{|c|}{$\begin{array}{c}\text { Vassouras de } \\
\text { almofada floral }\end{array}$} \\
\hline & $\mathbf{r}$ & $\mathrm{R}^{2}(\%)$ & $\mathbf{r}$ & $R^{2}(\%)$ & $\mathbf{r}$ & $R^{2}(\%)$ & $r$ & $\mathbf{R}^{2}(\%)$ & $\mathbf{r}$ & $\mathrm{R}^{2}(\%)$ & $r$ & $\mathbf{R}^{2}(\%)$ \\
\hline I & 0,455 & 76,95 & 0,402 & 72,88 & 0,414 & 73,85 & 0,348 & 68,05 & 0,123 & 35,83 & 0,208 & 51,23 \\
\hline II & 0,420 & 74,34 & 0,365 & 69,70 & 0,412 & 73,72 & 0,354 & 68,69 & 0,124 & 36,05 & 0,212 & 51,90 \\
\hline III & 0,584 & 84,90 & 0,501 & 80,57 & 0,434 & 75,40 & 0,497 & 79,82 & 0,283 & 61,23 & 0,481 & 78,75 \\
\hline IV & 0,484 & 78,94 & 0,444 & 76,18 & 0,428 & 74,92 & 0,396 & 72,37 & 0,189 & 48,18 & 0,276 & 60,37 \\
\hline $\mathrm{V}$ & 0,480 & 78,71 & 0,444 & 75,81 & 0,427 & 74,89 & 0,392 & 72,10 & 0,167 & 44,45 & 0,272 & 59,87 \\
\hline VI & 0,455 & 76,95 & 0,402 & 72,88 & 0,414 & 73,85 & 0,348 & 68,05 & 0,123 & 35,83 & 0,208 & 51,23 \\
\hline
\end{tabular}

*Método: I-ANOVA, modelo 1; II - ANOVA, modelo 2; III-1 componente principal: covariância; IV-1 componente principal: correlação; V-Análise estrutural: correlação (r médio); e VI-Análise estrutural: covariância. Cruz (2001).

TABELA 3 - Número mínimo de observações de acordo com o coeficiente de determinação, estimado por diferentes métodos, para produção e sintomatologia em cacaueiro (Theobromae cacao)

\begin{tabular}{|c|c|c|c|c|c|c|c|}
\hline \multirow[b]{2}{*}{ Método* } & \multicolumn{7}{|c|}{$\begin{array}{ll}R^{2} & \mathbf{0 , 8 0}\end{array}$} \\
\hline & $\mathbf{r}$ & Produção & $\begin{array}{l}\text { Frutos } \\
\text { Sadios }\end{array}$ & $\begin{array}{c}\text { Frutos com } \\
\text { Vassoura -de-bruxa }\end{array}$ & $\begin{array}{c}\text { Frutos com } \\
\text { Podridão-parda } \\
\end{array}$ & $\begin{array}{l}\text { Vassouras } \\
\text { vegetativas }\end{array}$ & $\begin{array}{c}\text { Vassouras de } \\
\text { almofada floral }\end{array}$ \\
\hline I & 0,455 & 5 & 6 & 6 & 8 & 29 & 15 \\
\hline II & 0,420 & 6 & 7 & 6 & 7 & 28 & 15 \\
\hline III & 0,584 & 3 & 4 & 5 & 4 & 10 & 4 \\
\hline IV & 0,484 & 4 & 5 & 5 & 6 & 17 & 11 \\
\hline V & 0,480 & 4 & 5 & 5 & 6 & 20 & 11 \\
\hline
\end{tabular}

*Método: I-ANOVA, modelo 1; II - ANOVA, modelo 2; III- $1^{\circ}$ componente principal: covariância; IV- $1^{\circ}$ componente principal: correlação; e V-Análise estrutural: correlação (r médio). Cruz (2001). 
alto nível de acurácia, considerando-se que se tratam de avaliações em nível de campo (Tabela 2). Embora a análise da repetibilidade tenha sido útil para indicar a acurácia dos resultados e o número mínimo de observações necessárias, sugere-se que a natureza perene do cacaueiro e as características de cada doença sejam consideradas como fatores importantes na aceitação desses números mínimos de observações.

Para as características produção, frutos sadios, frutos com podridão-parda e frutos com vassoura-de-bruxa, o número de observações requeridas no atual sistema de avaliação, considerando-se um $\mathrm{R}^{2}$ de 0,80 , variou de 3 a 8 (Tabela 3). Por outro lado, para as características vassoura vegetativa e vassoura de almofada floral, a maneira mais eficaz de avaliá-las será por inoculações controladas, posto que o número de observações requeridas no atual sistema seria superior a 10, à exceção do registrado no método III, para a característica vassoura de almofada floral (Tabela 3).

Conforme se pode observar, a progênie estudada segrega para várias características, inclusive para resistência à vassoura-de-bruxa e podridão-parda. Há grande amplitude de variação de todas as características, mostrando a importância da progênie para a realização de estudos de mapeamento genético em nível molecular na cultura do cacaueiro, visando a identificação de novos genes de resistência e de QTL's para características agronômicas de importância, bem como para o programa de melhoramento genético do cacaueiro.

A avaliação em condições de campo por quatro anos consecutivos permitiu identificar os indivíduos susceptíveis, minimizando as chances de falsos-resistentes. No entanto, os baixos índices de repetibilidade neste estudo exploratório com 67 plantas, indicam que a população ampliada deverá ser avaliada em diferentes ambientes, cujos resultados serão de grande importância agronômica. Além disso, os clones deverão ser inoculados artificialmente para incluir a avaliação de cada indivíduo frente à multiplicidade de patótipos e fatores ambientais, não necessariamente representados em cada local.

Esses resultados, obtidos em plantas com oito anos de idade, comprovaram a viabilidade dos estudos de QTLs em populações derivadas do cruzamento entre os clones SIC-864 e CCN-51; adicionalmente, serviram de base para a ampliação da população para 270 indivíduos, que serão utilizados no desenvolvimento de um mapa genético e na identificação de QTLs.

\section{AGRADECIMENTOS}

Ao "Common Fund of Commodities" (CFC), "International Cocoa Organization" (ICCO) e à Comissão Executiva do Plano da Lavoura Cacaueira (CEPLAC)-CFC/ ICCO/CEPLAC- "Biomol Project", pelo auxílio financeiro e pela concessão da bolsa de estudos para o curso de Mestrado do primeiro autor.

Ao Dr. Raul René Melendez Valle, pelas correções no "abstract” e ao Dr. José Luís Pires, pelos ajustes da análise estatística.

\section{REFERÊNCIAS BIBLIOGRÁFICAS}

ANDEBRHAN, T. Studies on the epidemiology and control of witches' broom disease of cocoa in the Brazilian Amazon. In: Proceeding of the $9^{\text {th }}$ International Cocoa Research Conference. Lomé, 1984. 1985. pp. 395-402.

BONDAR, G. Cacau branco na Bahia. Espécies e variedades de cacau. Boletim da Secretaria da Agricultura, Indústria e Comércio do Estado da Bahia 20:7-30. 1958.

CAMPO, E.C. \& ANDÍA, F.C. Cultivo y Beneficio del Cacao CCN51. Quito. El Conejo. 1997.

CRUZ, C.D. \& REGAZZI, A.J. Modelos Biométricos Aplicados ao Melhoramento Genético. $2^{\mathrm{a}}$ ed. Viçosa. Universidade Federal de Viçosa. 1997.

CRUZ, C.D. Programa Genes-versão Windows: aplicativo computacional em genética e estatística. Viçosa. Universidade Federal de Viçosa. 2001

CROUZILlAT, D., PHILLIPS W., FRITZ P. J. \& PÉTIARD V. Quantitative trait loci analysis in Theobroma cacao L. using molecular markers. Inheritance of polygenic resistance to Phytophthora palmivora in two related cacao populations. Euphytica 114:25-36. 2000.

DIAS, L.A.S. \& KAGEYAMA, P.Y. Repeatability and minimum harvest period of cacao (Theobroma cacao L.) in Southern Bahia. Euphytica 102:29-35. 1998.

GRAMACHO, I.C.P., MAGNO, A.E.S., MANDARINO, E.P. \& MATOS, A. Cultivo e Beneficiamento do Cacau na Bahia. $1^{\mathrm{a}}$ ed. Ilhéus. CEPLAC/CEDEX. 1992.

LIBERATO, J.R., CRUZ, C.D., TATAGIBA, J.S. \& ZAMBOLIM, L. Minimum number of assessment times to compare chemical control treatments for papaya fruit anthracnose. Fitopatologia Brasileira 29:659-662. 2004.

LUZ, E.D.M.N., BEZERRA, J.L., RESENDE, M.L.V. \& OLIVEIRA, M.L. Cacau (Theobroma cacao L.) Controle de doenças. In: Ribeiro do Vale, F.X. \& Zambolim, L. (Eds.) Controle de Doenças de Plantas-Grandes Culturas. Viçosa. UFV, 2v. 1997. pp. 617-622.

LUZ, E.D.M.N \& SILVA, S.D.V.M. Podridão-parda dos frutos, cancro e outras doenças causadas por Phytophthora no cacaueiro. In: Luz, E.D.M.N., Santos, A.F., Matsuoka, K. \& Bezerra, J.L. (Eds.). Doenças Causadas por Phytophthora no Brasil. Livraria Rural, Campinas. 2001. pp.175-265.

MEDEIROS, A.G. Combate à Podridão-Parda com o Emprego do Cacau Catongo. Ilhéus. CEPLAC/CEPEC. 1965.

MEDEIROS, A.G. Sporulation of Phytophthora palmivora (Butl.) Butl. in relation to epidemiology and chemical control of black pod disease. (PhD. Thesis). Riverside. University of California. 1977. NIELLA, G.R. Frutificação in vitro, caracterização molecular e patogênica de Crinipellis perniciosa (Stahel) Singer em Theobroma cacao L. (Tese de Doutorado). Lavras. Universidade Federal de Lavras. 2000.

PEREIRA, J.L.M., RAM, A., FIGUEIREDO, J.M. \& ALMEIDA, L.C.C. Primeira ocorrência de vassoura-de-bruxa na principal região 
produtora de cacau do Brasil. Agrotrópica 1:79-81. 1989.

PINTO, L.R.M \& PIRES, J.L. Seleção de Plantas de Cacau Resistentes à Vassoura-de-bruxa. Ilhéus. CEPLAC/CEPEC.1998.

PIRES, J.L. Avaliação quantitativa e molecular de germoplasma para o melhoramento do cacaueiro com ênfase na produtividade, qualidade de frutos e resistência a doenças. (Tese de Doutorado). Viçosa. Universidade Federal de Viçosa. 2003.

QUEIROZ, V.T., GUIMARÃES, C.T., ANHERT, D., SCHUSTER,
I., DAHER, R.T., PEREIRA, M.G., MIRANDA, V.R.M., LOGUERCIO, L.L., BARROS, E.G. \& MOREIRA, M.A. Identification of a major QTL in cocoa (Theobroma cacao L.) associated with resistance to witches' broom disease. Plant Breeding 122:268-272. 2003.

WADSWORTH, R.M., FORD, C.S., TURNBUlL, C.J. \& HADLEY, P. International Cocoa Germplasm Database v. 5.2. Euronext.life/University of Reading. UK. 2003. CD-ROOM. 